\title{
A fluorometric method for the assay of protein kinase activity
}

\author{
Bruno E. Rojas ${ }^{\mathrm{a}}$, Franco Santin ${ }^{\mathrm{b}}$, Rita M. Ulloa ${ }^{\mathrm{b}}$, Alberto A. Iglesias ${ }^{\mathrm{a}}$, Carlos M. Figueroa, ${ }^{\mathrm{a}, *}$ \\ a Instituto de Agrobiotecnología del Litoral, UNL, CONICET, FBCB, Colectora Ruta Nacional $168 \mathrm{Km}$ 0, 3000 Santa Fe, Argentina \\ ${ }^{\mathbf{b}}$ Instituto de Investigaciones en Ingeniería Genética y Biología Molecular, UBA, CONICET, FCEN, Vuelta de Obligado 2490, 1428 Buenos Aires, Argentina
}

A R T I C L E I N F O

Keywords:

Protein kinase

Phosphorylation

Non-radioactive assay

Enzyme kinetics

\begin{abstract}
A B S T R A C T
Protein kinases constitute one of the largest protein families in nature. Current methods to assay their activity involve the use of radioactive ATP or very expensive reagents. In this work, we developed a highly sensitive, cost-effective and straightforward protocol to measure protein kinase activity using a microplate layout. Released ADP is converted into $\mathrm{NAD}^{+}$, which is quantified by its fluorescent properties after alkaline treatment (linear range 0-10 nmol ADP). To validate our protocol, we characterized a recombinant calcium-dependent protein kinase from potato. Overall, this tool represents a critical step forward in the functional characterization of protein kinases.
\end{abstract}

Protein phosphorylation is one of the most studied post-translational modifications because it regulates almost every aspect of cellular function [1,2]. Eukaryotic protein kinases (PKs, EC 2.7.11.-) transfer a single phosphoryl group from the $\gamma$ position of ATP to the hydroxyl groups of serine, threonine and tyrosine residues in protein substrates (Supplemental Fig. S1) [3]. Abnormal protein phosphorylation has been linked to several diseases; thus, PKs are intensively studied in drugdiscovery experiments [4]. The main difficulty to assay PKs is their intrinsic, low turnover rates $\left(10^{-2}-10^{-5} \mathrm{~s}^{-1}\right)$ [5]. Several methods have been developed to measure PK activity (Supplemental Fig. S1), but only those based on ADP quantification can be applied to all PK/substrate combinations [6].

The radioactive assay (Supplemental Fig. S1) was the first method used to measure PK activity and is considered the gold standard due to its high sensitivity and robustness [7-10]. As drawbacks, it is timeconsuming and generates a large amount of radioactive waste. Nonradioactive methods to assay PK activity are based on peptide or ADP detection (Supplemental Fig. S1). In general, peptide-dependent methods have low sensitivity and can neither be adapted to PKs with unknown motif preference nor used with native proteins as substrates. Among methods to detect ADP, Transcreener $\mathrm{ADP}^{2}$ Kinase Assay (BellBrook Labs) is the only one that allows direct detection of ADP; it is highly sensitive but very expensive. Coupled methods are based on the use of enzymes to detect the products of the phosphorylation reaction, being ADP-Glo (Promega) the main assay currently available on the market. It measures released ADP using an enzymatic tandem to generate a luminescent signal. This is a highly sensitive method but it is quite expensive and sensitive to compounds that inhibit luciferase $[11,12]$.

In this work, we adapted the enzymatic tandem pyruvate kinase/ lactate dehydrogenase to assay PK activity [9]. Released ADP is converted into $\mathrm{NAD}^{+}$, which can be quantified using a fluorescence detector after the alkaline treatment initially described by Kaplan et al. [13] and further adapted by other authors [14,15] (Supplemental Fig. S2). We characterized a plant PK in parallel with the radioactive method, the ADP-Glo reagent and the fluorometric method. We show this is a cost-effective method, suitable to assay PK activity without radioactive ATP and with any type of substrate.

Solanum tuberosum Calcium Dependent Protein Kinase 1 (StCDPK1) was expressed as described by Santin et al. [16], with minor modifications. Transformed cells were grown in LB medium supplemented with $100 \mu \mathrm{g} \mathrm{ml}^{-1}$ ampicillin and induced with $0.5 \mathrm{mM}$ isopropyl- $\beta$-D-1thiogalactopyranoside for $16 \mathrm{~h}$ at $30{ }^{\circ} \mathrm{C}$ and $180 \mathrm{rpm}$. Cells were collected by centrifugation, resuspended in lysis buffer [ $25 \mathrm{mM}$ Tris- $\mathrm{HCl}$ $\mathrm{pH}$ 8.0, $300 \mathrm{mM} \mathrm{NaCl}, 5 \%$ (v/v) glycerol and $10 \mathrm{mM}$ imidazole], disrupted by sonication and centrifuged twice at $16000 \times g$ for $20 \mathrm{~min}$ at $4{ }^{\circ} \mathrm{C}$. The crude extract was loaded onto a 1-ml HisTrap HP column (GE Healthcare) previously equilibrated with lysis buffer. The enzyme was eluted with a linear imidazole gradient $(10-300 \mathrm{mM})$ in lysis buffer. Fractions containing PK activity were pooled, concentrated and stored at $-80^{\circ} \mathrm{C}$ until use.

StCDPK1 activity was assayed as described by Raíces et al. [17]. Briefly, the enzyme was incubated for $5 \mathrm{~min}$ in $20 \mathrm{mM}$ Tris- $\mathrm{HCl} \mathrm{pH} 7.5$, $10 \mathrm{mM} \mathrm{MgCl}_{2}, 1 \mathrm{mM}$ DTT, $1 \mathrm{mM} \mathrm{CaCl}_{2}, 50 \mu \mathrm{M}$ ATP and $100 \mu \mathrm{M}$ Syntide-

\footnotetext{
* Corresponding author.

E-mail addresses: brojas@santafe-conicet.gov.ar (B.E. Rojas), francosantin@gmail.com (F. Santin), rulloa@dna.uba.ar (R.M. Ulloa), iglesias@fbcb.unl.edu.ar (A.A. Iglesias), carfigue@fbcb.unl.edu.ar (C.M. Figueroa).
} 


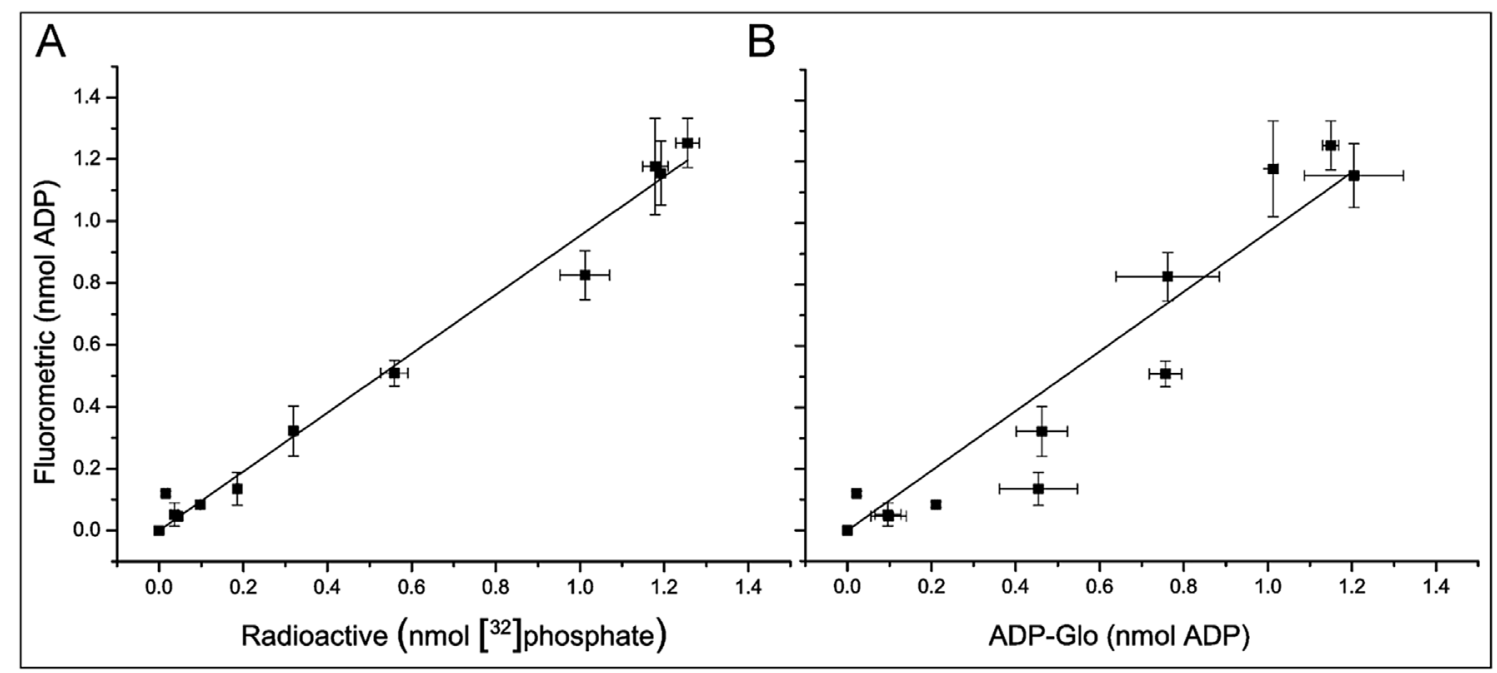

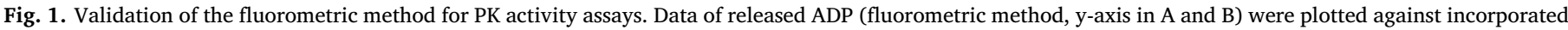

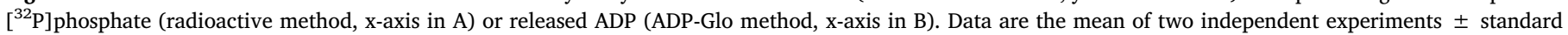
error.

Table 1

Characterization of StCDPK1 with three different methods. Kinetic parameters were calculated by fitting activity data to a modified Hill equation, as described in the main text.

\begin{tabular}{llll}
\hline Parameter & Radioactive & ADP-Glo & Fluorometric \\
\hline$V_{\max }\left(\mathrm{U} \mathrm{mg}^{-1}\right)$ & $1.21 \pm 0.04$ & $1.2 \pm 0.1$ & $1.23 \pm 0.06$ \\
ATP $S_{0.5}(\mu \mathrm{M})$ & $63 \pm 6$ & $54 \pm 17$ & $78 \pm 11$ \\
$n_{\mathrm{H}}$ & $1.5 \pm 0.2$ & $0.8 \pm 0.1$ & $1.3 \pm 0.2$ \\
Adjusted $\mathrm{R}^{2}$ & 0.99 & 0.98 & 0.99 \\
\hline
\end{tabular}

2 peptide at $30{ }^{\circ} \mathrm{C}$ (a detailed list of all reagents used as well as preparation and storage considerations are available in Supplemental Table S1). Activity measurements with the radioactive method were done in a final volume of $20 \mu$ l, following a previously described protocol [10]. Activity measurements with the ADP-Glo reagent (Promega) were done in a final volume of $5 \mu \mathrm{l}$, according to the manufacturer's instructions.

Reactions with the fluorometric assay were performed in a final volume of $20 \mu \mathrm{l}$ in black 96-well microplates (Thermo Scientific) as described above, with the addition of the system necessary to convert released ADP into $\mathrm{NAD}^{+}$( $2 \mathrm{mM}$ phosphoenolpyruvate, $2 \mathrm{mM} \mathrm{NADH}, 1$ $\mathrm{U}$ lactate dehydrogenase and $1 \mathrm{U}$ pyruvate kinase) to the PK reaction. Reactions were stopped with $20 \mu \mathrm{l} 0.3 \mathrm{M} \mathrm{HCl}$ and incubated for $20 \mathrm{~min}$ at room temperature to remove excess NADH (Supplemental Fig. S3). Then, $170 \mu \mathrm{l} 9 \mathrm{M} \mathrm{NaOH}$ were added and samples were incubated at room temperature in the dark for $60 \mathrm{~min}$ to develop the $\mathrm{NAD}^{+}$alkaline derivates. Fluorescence was quantified in a fluorometer (Fluoroskan Ascent FL, Thermo Scientific) using excitation and emission filters of 355 and $460 \mathrm{~nm}$, respectively, with an integration time of $20 \mathrm{~ms}$. The amount of generated ADP was calculated using an ADP standard curve constructed using the same conditions. A detailed step by step procedure with key experimental details is presented in Supplemental Fig. S2. Data were analyzed with OriginPro 8 (OriginLab Corporation). Kinetic parameters were obtained by fitting data of enzyme activity versus substrate concentration using a modified Hill equation: $v=V_{\max }{ }^{*} \mathrm{~S}^{n \mathrm{H}} /\left(S_{0.5}{ }^{n \mathrm{H}}+\mathrm{S}^{n \mathrm{H}}\right)$; where $v$ is the initial velocity, $S_{0.5}$ is the concentration of substrate (S) that produces $50 \%$ of the maximal velocity $\left(V_{\max }\right)$, and $n_{\mathrm{H}}$ is the Hill coefficient. One unit (U) is defined as the amount of enzyme that catalyzes the formation of $1 \mu \mathrm{mol}$ of ADP per minute under the specified assay conditions.

The radioactive assay detects phosphopeptide formation in the nanomolar range; thus, we optimized conditions to measure ADP in such a range. Standard curves were made in a final volume of $20 \mu \mathrm{l}$ with increasing amounts of ADP $(0-0.5 \mathrm{mM} ; 0-10 \mathrm{nmol})$. Curves were linear with a slope of $420 \pm 7 \mathrm{RFU} \mathrm{mM}{ }^{-1}$ (Adjusted $\mathrm{R}^{2}=1.00, P<0.001$; Supplemental Figs. S4A-B). We obtained identical results when calibration curves were performed with $\mathrm{NAD}^{+}$(Supplemental Fig. S4 A-B), indicating complete conversion of $\mathrm{ADP}$ into $\mathrm{NAD}^{+}$with the pyruvate kinase/lactate dehydrogenase system. Under our assay conditions, limits of detection and quantification for ADP were 0.05 and $0.15 \mathrm{nmol}$, respectively (Supplemental Fig. S4C). The fluorometric method showed adequate reproducibility, according to the coefficient of variation (CV) obtained for calibration curves (average $<5 \%$ ) and StCDPK1 activity assays (average $<15 \%$ ). We also obtained a good signal to background ratio (S:B) and a $\mathrm{Z}$ factor $>0.5$ above $15 \mu \mathrm{M}$ ADP (Supplemental Fig. S4D), suggesting potential application in highthroughput screenings. Equations used for calculating LOD, LOQ, S:B and $\mathrm{Z}$ factor are presented in Supplemental Information S1.

To validate our method, we performed StCDPK1 activity assays with our fluorometric method in parallel with the radioactive and ADP-Glo methods. We observed a linear correlation (in the analyzed range of product formation, $0-1 \mathrm{nmol}$ ) between the fluorometric and radioactive methods (Slope $=1.04 \pm 0.03, \mathrm{R}^{2}=0.99, P<0.001$; Fig. $1 \mathrm{~A}$ ). Similar results were obtained between the fluorometric method and the ADP-Glo reagent $\quad$ Slope $=0.98 \pm 0.07, \mathrm{R}^{2}=0.95, \quad P<0.001$; Fig. 1B).

Kinetic parameters for StCDPK1 using Syntide-2 as substrate determined with the fluorometric method were similar to those obtained in parallel with the radioactive method and the ADP-Glo reagent (Table 1 and Supplemental Fig. S4), although slightly different to the ones reported by Grandellis et al. [18]. We also obtained identical results with the fluorometric and radioactive methods when StCDPK1 activity was assayed with myelin basic protein as substrate $(1.5 \pm 0.3$ and $1.6 \pm 0.3 \mathrm{mU} \mathrm{mg}^{-1}$, respectively).

The fluorometric method described in this work is intended for the functional characterization of PKs. Our method is highly sensitive, which makes it suitable for activity assays in small reaction volumes, either with peptides or proteins as substrates. This is of great interest because PKs phosphorylate proteins more efficiently than artificial peptides [3]. Another advantage of using pyruvate kinase in the PK reaction is that released ADP is recycled back to ATP, thus maintaining a constant substrate concentration [19] (Supplemental Fig. S2). This ensures initial velocity conditions over the course of the enzymatic reaction and avoids PK inhibition by ADP [19,20].

The main drawback of our method is that it cannot be used to 
reliably assay PK activity in crude extracts. This is mainly due to the presence of ATPases and non-specific phosphatases, which release ADP and thus increase reaction blanks [12]. Also, the flourometric method could not be employed to assay PKs with ATP $S_{0.5}$ values close to or lower than its detection limit [21]. Besides that, we envisage that our assay will be of great help for the biochemical characterization of PKs. It is worth mentioning that the cost per reaction of the fluorometric method is significantly lower than the radioactive method (5-fold) and the ADP-Glo reagent (19-fold). Kinetic parameters obtained for StCDPK1 with all methods used herein (fluorometric, radioactive and ADP-Glo) are in good agreement with those previously reported for other CDPKs (Table 1 and Supplemental Table S2). Therefore, we conclude that the fluorometric method developed in this work represents an important tool better understand the function of PKs.

\section{Acknowledgements}

This work was supported by Agencia Nacional de Promoción Científica y Tecnológica (PICT 20150642 to CMF and PICT 20151767 to AAI), Universidad Nacional del Litoral (CAI + D 2016 to AAI) and Max Planck Gesellschaft (Partner Group for Plant Biochemistry to CMF). BER is a Fellow and RMU, AAI and CMF are Researchers from CONICET.

\section{Appendix A. Supplementary data}

Supplementary data related to this article can be found at https:// doi.org/10.1016/j.ab.2018.07.018.

\section{References}

[1] G. Manning, The protein kinase complement of the human genome, Science 298 (2002) 1912-1934, https://doi.org/10.1126/science.1075762.

[2] P. Cohen, The origins of protein phosphorylation, Nat. Cell Biol. 4 (2002) E127-E130, https://doi.org/10.1038/ncb0502-e127.

[3] J.A. Adams, Kinetic and catalytic mechanisms of protein kinases, Chem. Rev. 101 (2001) 2271-2290, https://doi.org/10.1021/cr000230w.

[4] P. Cohen, Protein kinases - the major drug targets of the twenty-first century? Nat. Rev. Drug Discov. 1 (2002) 309-315, https://doi.org/10.1038/nrd773.

[5] T.W. Traut, The limits for life define the limits for enzymes, Allosteric Regul. Enzym, Springer, Boston, MA, 2008pp. 29-49. doi:10.1007/978-0-387-72891-9_2.
[6] Y. Jia, C.M. Quinn, S. Kwak, R.V. Talanian, Current in vitro kinase assay technologies: the quest for a universal format, Curr. Drug Discov. Technol. 5 (2008) 59-69, https://doi.org/10.2174/157016308783769414.

[7] J.J. Witt, R. Roskoski, Rapid protein kinase assay using phosphocellulose-paper absorption, Anal. Biochem. 66 (1975) 253-258, https://doi.org/10.1016/00032697(75)90743-5.

[8] D.B. Glass, R.A. Masaracchia, J.R. Feramisco, B.E. Kemp, Isolation of phosphorylated peptides and proteins on ion exchange papers, Anal. Biochem. 87 (1978) 566-575, https://doi.org/10.1016/0003-2697(78)90707-8.

[9] R. Roskoski, Assays of protein kinase, Methods Enzymol. 99 (1983) 3-6, https:// doi.org/10.1016/0076-6879(83)99034-1.

[10] C.J. Hastie, H.J. Mclauchlan, P. Cohen, Assay of protein kinases using radiolabeled ATP : A Protocol 1 (2006) 968-971, https://doi.org/10.1038/nprot.2006.149.

[11] G.S.A. Zegzouti Hicham, US20100075350A1.pdf, U. S. Jpn. Outlook 2010/0075350 A1, 2010.

[12] H. Zegzouti, M. Zdanovskaia, K. Hsiao, S.A. Goueli, ADP-Glo: a bioluminescent and homogeneous ADP monitoring assay for kinases, Assay Drug Dev. Technol. 7 (2009) 560-572, https://doi.org/10.1089/adt.2009.0222.

[13] N.O. Kaplan, S.P. Colowick, C. Carr Barnes, Effect of alkali on diphosphopyridine nucleotide, J. Biol. Chem. 191 (1951) 461-472.

[14] O.H. Lowry, N.R. Roberts, J.I. Kapphan, The fluorometric measurement of pyridine nucleotides, J. Biol. Chem. 224 (1957) 1047-1064.

[15] G.E. Tsotsou, A. Edward, G. Cass, G. Gilardi, High throughput assay for cytochrome P450 BM3 for screening libraries of substrates and combinatorial mutants, Biosens. Bioelectron. 17 (2002) 119-131, https://doi.org/10.1016/S0956-5663(01) 00285-8.

[16] F. Santin, S. Bhogale, E. Fantino, C. Grandellis, A.K. Banerjeeb, R.M. Ulloa, Solanum tuberosum StCDPK1 is regulated by miR390 at the posttranscriptional level and phosphorylates the auxin efflux Carrier StPIN4 in vitro, a potential downstream target in potato development, Physiol. Plantarum 159 (2017) 244-261, https://doi. org/10.1111/ppl.12517.

[17] M. Raíces, J.M. Chico, M.T. Téllez-Iñón, R.M. Ulloa, Molecular characterization of StCDPK1, a calcium-dependent protein kinase from Solanum tuberosum that is induced at the onset of tuber development, Plant Mol. Biol. 46 (2001) 591-601, https://doi.org/10.1023/A:1010661304980.

[18] C. Grandellis, V. Giammaria, M. Bialer, F. Santin, T. Lin, D.J. Hannapel, R.M. Ulloa, The novel Solanum tuberosum calcium dependent protein kinase, StCDPK3, is expressed in actively growing organs, Planta 236 (2012) 1831-1848, https://doi.org/ 10.1007/s00425-012-1732-9.

[19] Paul F. Cook, E. Maynard, Neville Jr., Kent E. Vrana, F. Thomas Hartl, J. Robert Roskoski, Adenosine cyclic 3',5'-monophosphate dependent protein kinase: kinetic mechanism for the bovine skeletal muscle catalytic subunit, Biochemistry 21 (1982) 5794-5799.

[20] D.W. Bolen, Juerg Stingelin, H. Neal Bramson, E. T. K, Stereochemical and kinetic studies on the action of the catalytic subunit of bovine cardiac muscle adenosine 3',5'-monophosphate dependent protein kinase using metal ion complexes of $\mathrm{ATP} \mathrm{S}^{+}$, Biochemistry 19 (1980) 1176-1182.

[21] Z.A. Knight, K.M. Shokat, S. Francisco, S. Francisco, Features of selective kinase inhibitors, Chem. Biol. 12 (2005) 621-637, https://doi.org/10.1016/j.chembiol. 2005.04.011. 